\title{
Use of Personal Digital Assistants for Instant Access to Drug Information
}

\author{
Lloyd Matowe \\ Department of Pharmacy Practice, Faculty of Pharmacy, Kuwait University, Safat, Kuwait
}

\section{Key Words}

Personal digital assistant - Access to drug information

In today's world, evolution of computer technology appears to outpace all other innovations. Arguably it is those institutions, organisations and individuals who keep up with technological advancements that stay abreast of the field in today's competitive society. Traditionally, health care providers have used textbooks, formularies, compendia, guidelines and more recently online databases to access drug information. A large and rapid increase in medications over the years makes the provision of up-to-date drug information in a timely and costeffective manner a challenge.

The personal digital assistant (PDA), a handheld computing device also known as the palmtop computer, can greatly improve access to drug information, particularly at the point of delivery. The PDAs can support workflow, allow instant access to drug information and enable realtime access to health care data anytime and anywhere $[1,2]$.

In the USA, some pharmacy and medical schools have adopted this technology for teaching purposes [3-5]. In Kuwait, the Faculty of Pharmacy, Kuwait University, has acquired PDAs for all final-year pharmacy students. Stu- dents find these devices useful and convenient for accessing drug information, particularly during rotations in hospitals with clinicians.

For practising pharmacists, PDAs can help document a variety of clinical activities in the patient care setting. This is more important for clinical pharmacists who spend much of their time identifying, solving and preventing drug-related problems. Considering their busy working schedules, medical doctors could benefit substantially.

Basic features of a PDA drug reference database include the ability to search for a drug from a generic, trade or partial name, or from the drug's therapeutic classification or use. Dosing information, pharmacokinetic parameters, drug interaction, side-effects and contra-indication screening are also available. Other useful clinical applications of PDAs include the ability to perform calculations such as ideal body weight and creatinine clearance. Customisation of databases such as the addition of local drug lists is possible. For instance, we have added the Kuwait Drug List to the PDAs allocated to our pharmacy students.

For users to be able to store and retrieve drug information, the PDA requires software. Examples of drug information software include ePocrates, LexiDrugs, Apothecarium and the Tarascon ePharmacopoeia. ePocrates can be downloaded from the Worldwide Web free of charge.

\begin{tabular}{ll}
\hline KARGER & ( 2004 S. Karger AG, Basel \\
1011-7571/04/0135-0290\$21.00/0 \\
$\begin{array}{l}\text { Fax +4161306 12 34 } \\
\begin{array}{l}\text { E-Mail karger@karger.ch } \\
\text { www.karger.com }\end{array}\end{array}$ & $\begin{array}{l}\text { Accessible online at: } \\
\text { www.karger.com/mpp }\end{array}$
\end{tabular}

Dr. Lloyd Matowe, PhD, Assistant Professor

Department of Pharmacy Practice, Faculty of Pharmacy, Kuwait University PO Box 24923

Safat 13110 (Kuwait)

Tel. +965 531 2300, ext. 6034, E-Mail 1.matowe@hsc.kuniv.edu.kw 
Outside clinical practice, PDAs can be just as handy. The device is extremely useful as a personal organiser. In addition, the PDAs can be equipped with modems that allow access to the Internet. The user can also perform word-processing tasks on the go and send data to other users in the form of e-mail and e-mail attachments, database files and written documents.

To conclude, the PDA can be useful for instant access to drug information. Its portability makes it great value for clinicians at the bedside.
References

1 Fischer S, Stewart TE, Mehta S, Wax R, Lapinsky SE: Handheld computing in medicine. $\mathrm{J}$ Am Med Inform Assoc 2003;10:139-149.

2 Hogan R: ePocrates qRx 4.0. JAMA 2001;286: 229-230.

3 University of Iowa: PDA Project: http:// www.its.uiowa.edu/cs/sp/pda/PDA-ProjectHomePage.html (accessed September 22, 2003).

4 Moore L, Richardson BR, Williams RW: The USU medical PDA initiative: The PDA as an educational tool. Proc AMIA Symp, 2002, pp 528-532.

5 Bertling CJ, Simpson DE, Hayes AM, Torre D, Brown DL, Schubot DB: Personal digital assistants herald new approaches to teaching and evaluation in medical education. WMJ 2003; 102:46-50. 